\title{
Design and fabrication of chilli paste grinder
}

\author{
ABHAY KUMAR MISHRA, KAILASH CHANDRA YADAV, PRIYANK MISRA AND NIRBHAY KUMAR \\ MISHRA
}

\begin{abstract}
The traditional method of chilli paste processes essentially consist of two main unit operation namely blending of raw material and cooking of the chilli paste, accompanied by manual stirring. The transferring of blended food for cooking adds clean-up work and tends to waste time and energy. Substantive continuous stirring during the cooking process is essential, but time and labour consuming. In this study, a process design of the chilli paste machine has been developed with the aim to combine both the process of blending and agitated cooking in single application. A new design of machine called chilli paste machine has been successfully built with the intention to overcome the issues present in making chilli paste. It comprises of blade which enables blending and stirring of chilli paste during blending and cooking process, respectively. A heating plate is installed for the heating of the chilli paste the whole operation is controlled by a simple mechanism of Miniature Circuit Breaker. (M.C.B.) and Switches which enables the temperature control. The prototype machine was tested to ensure the performances of the machine design are met. The ready to serve batch of chilli paste was successfully produced using this newly designed machine.
\end{abstract}

KEY WORDS : Blending, Stirring, Heating, Chilli paste, Miniature circuit breaker (M.C.B), Switches

How to cite this Article : Mishra, Abhay Kumar, Yadav, Kailash Chandra, Misra, Priyank and Mishra, Nirbhay Kumar (2016). Design and fabrication of chilli paste grinder. Engg. \& Tech. in India, 7 (1) : 8-17. 